\title{
Therapeutic potential of mesenchymal stem cells for diabetes
}

\author{
Alvaro Moreira', Samuel Kahlenberg' and Peter Hornsby² \\ 1Department of Pediatrics, University of Texas Health Science Center-San Antonio, San Antonio, Texas, USA \\ 2Department of Physiology, Texas Research Park Campus, Barshop Institute for Longevity and Aging Studies, \\ San Antonio, Texas, USA
}

Correspondence should be addressed

to A Moreira

Email

moreiraa@uthscsa.edu

\begin{abstract}
Mesenchymal stem cells (MSCs) are self-renewing multipotent cells that have the capacity to secrete multiple biologic factors that can restore and repair injured tissues. Preclinical and clinical evidence have substantiated the therapeutic benefit of MSCs in various medical conditions. Currently, MSCs are the most commonly used cell-based therapy in clinical trials because of their regenerative effects, ease of isolation and low immunogenicity. Experimental and clinical studies have provided promising results using MSCs to treat diabetes. This review will summarize the role of MSCs on tissue repair, provide emerging strategies to improve MSC function and describe how these processes translate to clinical treatments for diabetes.
\end{abstract}

\author{
Key Words \\ - mesenchymal stem cell \\ - tissue regeneration \\ - diabetes \\ - endocrine
}

Journal of Molecular

Endocrinology

(2017) 59, R109-R120

\section{Introduction}

Advances in stem cell biology have seen the rise of an exciting new field of research known as regenerative medicine. Regenerative medicine is a multidisciplinary branch of translational research that aims at repairing injured tissues to restore normal cellular function. To date, the cell population most commonly studied in clinical trials includes mesenchymal stem/stromal cells (MSCs). The therapeutic potential of MSCs is based on their ease of isolation, ability to differentiate into multiple cell types, low immunogenicity and most importantly their release of biologic factors shown to alleviate impaired tissues.

MSCs are multipotent cells, of mesodermal origin, that characteristically: (i) adhere to plastic and selfrenew, (ii) express specific surface antigen markers (CD73, CD90, CD105) and (iii) at a minimum, have the ability to differentiate into osteocytes, adipocytes or chondrocytes (Dominici et al. 2006). MSCs are widely distributed in the body and can therefore be isolated from multiple sources, including the bone marrow, heart, bodily fluids, skin and perinatal tissues. MSCs react to microenvironmental changes $(\mathrm{pH}$, oxygen, stress) by releasing immune modulatory and trophic factors known to regenerate injured cells and tissues (Caplan \& Correa 2011). Experimental findings in neurodegenerative and cardiovascular disease have supported the rapid growth of cell-based research (Murphy et al. 2013). To date, 695 US clinical trials are testing the utility of MSCs as therapeutic agents for an array of medical conditions.

The aim of this review is to provide a concise summary of the existing literature evaluating MSCs as novel therapeutic agents for diabetes mellitus. Additionally, this focused review will discuss recent methods used to bolster stem cell performance and how these discoveries are translating into endocrine research.

\section{Available and renewable sources of MSCs}

In 2012, Shinya Yamanaka was one of the awardees of the Nobel Prize in Physiology or Medicine for discovering that

Published by Bioscientifica Ltd 
mature cells can be reprogrammed into pluripotent cells. This remarkable technique is an excellent and readily available source of autologous stem cells that overcomes issues with cell/tissue rejection. Bone marrow and adipose tissue are another source for MSCs but their drawback is that invasive instrumentation is necessary to collect the tissue.

An emerging approach to retrieve MSCs in a noninvasive, ethically sound manner, and is traditionally considered medical waste includes the placenta and/or the umbilical cord (Nagamura-Inoue \& Mukai 2015). Furthermore, cells from these nascent tissues are postulated to have higher proliferative and differentiation abilities, as well as a heightened ability to express paracrine factors when compared to other MSC tissue sources. In the United States, the Centers for Disease Control and Prevention approximates 4 million births per year and 2.5 million deaths per year, which results in a surplus of MSCs available from perinatal tissue.

\section{Isolation of MSCs from the human umbilical cord}

Studies have established that MSCs can be isolated, expanded and cryopreserved from both umbilical cord blood and Wharton's jelly (umbilical cord matrix). However, advantages to the isolation of MSCs from the Wharton's jelly (WJ) include: a higher yield, more homogenous stem cell population, increased likelihood of successful MSC isolation and better ability to differentiate into insulin-producing cells (Weiss \& Troyer 2006, El-Demerdash et al. 2015, Vangsness et al. 2015, Arutyunyan et al. 2016). Several techniques have been described for the isolation of WJ-MSCs, but the two most common methods include an enzymatic digestion of cord tissue or an explant culture method (Fig. 1).

\section{Enzymatic method}

In this method, the umbilical cord $\mathrm{WJ}$ tissue is exposed to enzymes that disrupt the collagen matrix and hence releases cells into the underlying solution. The solution is then collected into a conical tube that is centrifuged to separate the pellet (cells) from the suspension. The supernatant is removed and the cells are plated on a tissue culture dish with stem cell media. Collagenase, hyaluronidase, trypsin and dispase are examples of enzymes used to dissociate WJ-MSCs from the matrix (Bruyn et al. 2011, Azandeh et al. 2012, Rostamzadeh et al. 2015).

\section{Explant method}

The derivation of MSCs under this method relies on the direct transfer of dissected umbilical cord tissue fragments onto a tissue culture dish (Fong et al. 2011, Mori et al. 2015, Talaei-Khozani et al. 2015). The culture dish is filled with media that stimulates the propagation of stem cells. Adherence of the WJ umbilical cord tissue to the bottom of the culture dish allows the migration of stem cells from the cord onto the surface of the dish. Within the first week, cells are visibly adherent to the surface of the plastic dish, at which point the tissue can be removed.

Although this technique is simple and involves less manipulation of the umbilical cord tissue, many researchers argue that this protocol results in a longer period for the cells to reach confluency when compared to the enzymatic method (Salehinejad et al. 2012, Hiew et al. 2016).

\section{Flow cytometric characterization of MSCs}

After growing the cells in a humidified incubator at $37^{\circ} \mathrm{C}$ with $5 \% \mathrm{CO}_{2}$ with stem cell media, the International

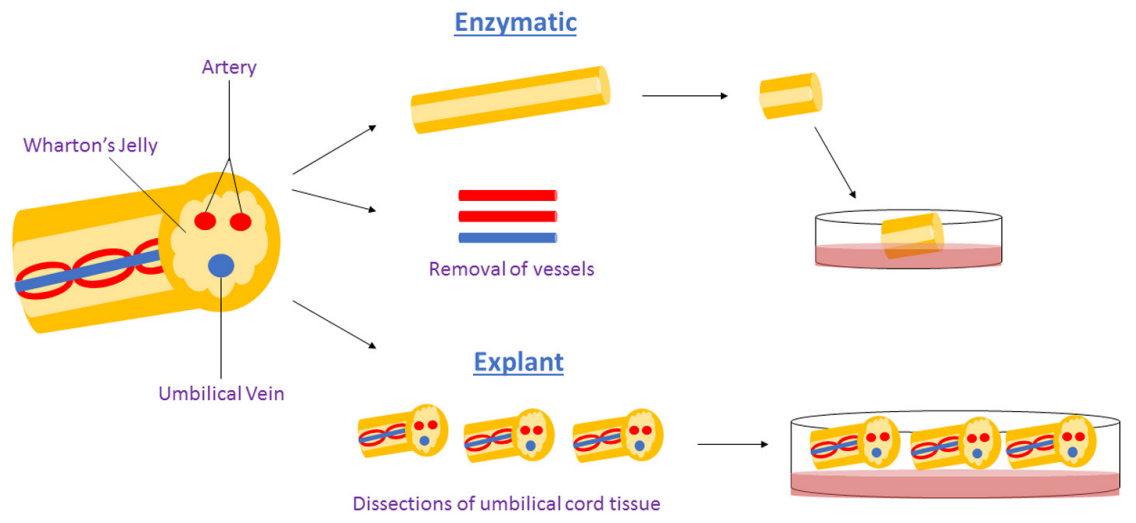

Figure 1

Enzymatic vs explant method for obtaining WJ-MSCs Wharton's jelly-derived mesenchymal stem cells. http://jme.endocrinology-journals.org DOI: 10.1530/JME-17-0117
๑ 2017 Society for Endocrinology Printed in Great Britain
Published by Bioscientifica Ltd 
Society for Cellular Therapy states that cells must express specific cell surface antigen markers to meet the definition of an MSC (Dominici et al. 2006). Mesenchymal cells from the umbilical cord should express $\geq 95 \%$ of CD 73 , CD 90 and CD 105. Furthermore, MSCs should express $\leq 2 \%$ of CD 14 or CD 11 b, CD34, CD 45, CD 19 or CD $79 \alpha$ or HLA-DR, as they are markers of hematopoietic differentiation.

\section{Differentiating MSCs into fat, bone and cartilage}

MSCs are idealized because of their multilineage potential and have proven to consistently differentiate into at least three specialized cell types - chondrocytes, osteoblasts and adipocytes. Cells should be stained with Alcian blue or collagen type II to demonstrate chondrocyte differentiation, Alizarin Red or von Kossa for osteoblast delineation and Oil Red $\mathrm{O}$ to show an adipocyte lineage (Birmingham et al. 2012, Mauck et al. 2006, Boeuf et al. 2010, Thibault et al. 2010, Scott et al. 2011, Baglio et al. 2015, Westhrin et al. 2015). Additional articles have reported the successful differentiation of MSCs into insulin-producing cells, Schwann cells and neurons (Keilhoff et al. 2006, Moshtagh et al. 2013, Feng et al. 2014). Figure 2 depicts a WJ-MSC that has adhered to plastic, expresses MSC surface antigens, that has also undergone differentiation into three cell types.
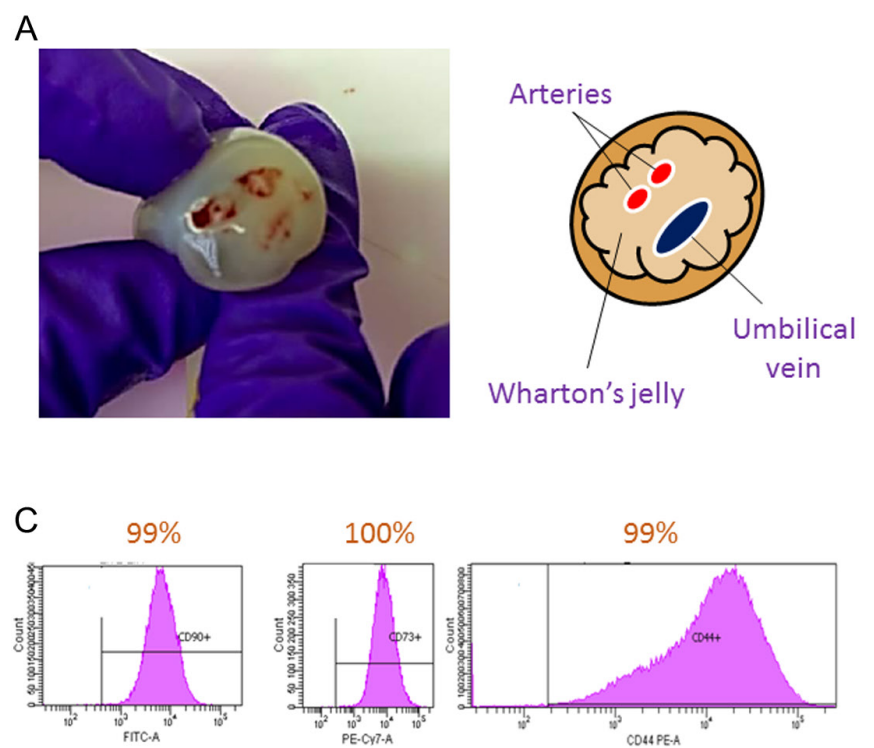

$\operatorname{CD} 90$

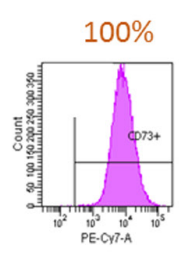

CD73

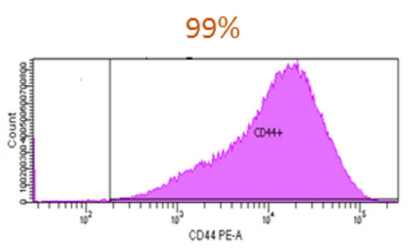

CD44

\section{MSCs stimulate tissue repair}

It is well established that the beneficial outcomes of MSCs occur through a paracrine release of biologic factors, rather than engraftment of cells into the recipient tissue. For purposes of this review, studies examining the regenerative properties of MSCs will be generalized into the following major themes: vascular development, antiinflammation and anti-fibrosis (Fig 3).

\section{Vascular development}

Angiogenesis, the formation of new blood vessels, is a vital process in tissue wound healing that is a targeted by many pharmacologic agents to treat disorders such as myocardial ischemia, ischemic stroke and diabetic retinopathy (Hammes et al. 2011, Johnson \& Wilgus 2014). Preclinical studies in cardiac and brain ischemia support the concept that MSCs improve structural and functional outcomes by repairing and stimulating the growth of blood vessels (Acosta et al. 2013, Hsuan et al. 2016). The angiogenic properties of MSCs are mediated through the release of hypoxia inducible factor, vascular endothelial growth factor, angiopoietin and erythropoietin. (Wei et al. 2012). The ability to repair vascular injury after administration of MSCs has been supported in studies of diabetic peripheral vascular disease, cutaneous wound repair and bone necrosis (Paneni et al. 2013, Arno et al. 2014, Fan et al. 2015).

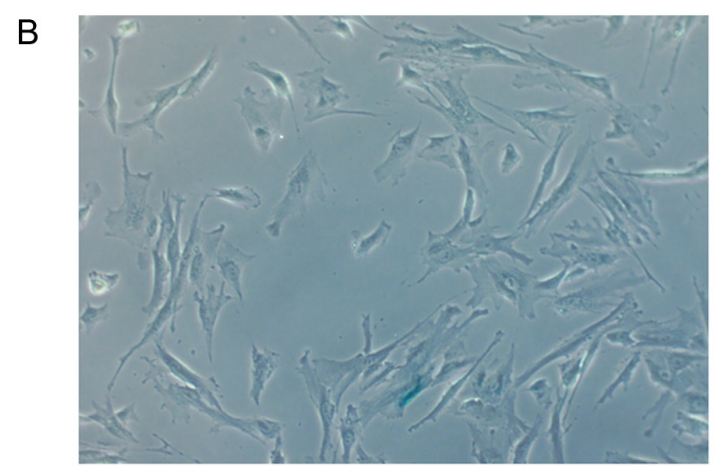

D

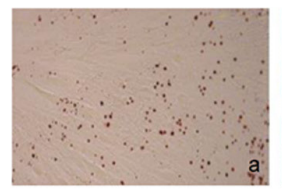

Osteogenic

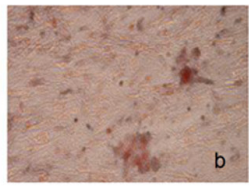

Adipogenic

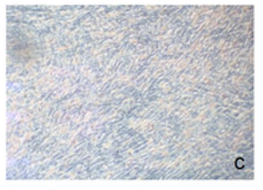

Chondrogenic

Figure 2

Characterization of WJ-MSCs. (A) Cross-section of human umbilical cord. (B) Plastic adherence of fibroblast-like appearance of WJ-MSCs. Magnification at 10x. (C) Flow cytometry of WJ-MSC surface antigen markers. (D) Multilineage differentiation of WJ-MSCs into (a) osteogenic (Alizarin Red stain) cells, (b) adipogenic (Oil Red O stain) and (c) chondrogenic (Alcian blue) cells. Magnification at 10x.

http://jme.endocrinology-journals.org DOI: 10.1530/JME-17-0117
C 2017 Society for Endocrinology Printed in Great Britain
Published by Bioscientifica Ltd 


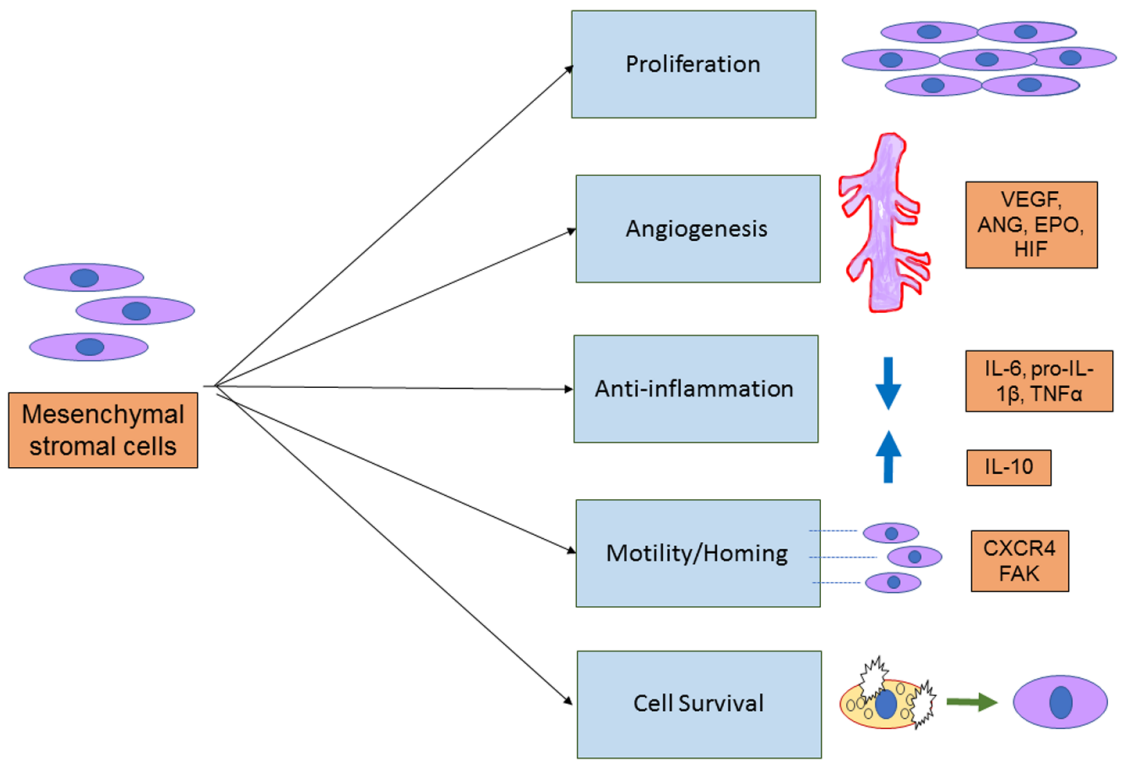

Figure 3

Therapeutic effects of mesenchymal stem cells. ANG-angiopoietin; EPO-erythropoietin; FAK-focal adhesion kinase; HIF-hypoxia inducible factor; TNF-tumor necrosis factor; VEGF-vascular endothelial growth factor.

\section{Immunomodulation}

Although inflammation is the body's natural response to protect against harmful stimuli, excessive or prolonged inflammatory stress can be detrimental to cells and tissues. For instance, chronic inflammation has now emerged as an important contributor to the pathogenesis of metabolic syndrome (Monteiro \& Azevedo 2010). As such, investigators have begun exploring the interactions between inflammation and MSC therapy. In particular, MSCs modulate key inflammatory cell types, including T-cells, natural killer cells, B-cells and dendritic cells (Wang et al. 2012). The MSC interaction with these innate and adaptive immune cells results in downregulation of inflammatory markers (interleukin-1 $\beta$, tumor necrosis factor $\alpha$, interleukin-6) as well as an increase in protective cytokines (interleukin-10, prostaglandin $\mathrm{E}_{2}$, indoleamine 2, 3-dioxygenase). Bone degenerative studies treated with MSCs also highlight their ability to decrease the secretion of macrophage inflammatory protein and monocyte chemoattractant protein (Pers et al. 2015). In rodent models of acute lung injury, Gupta and coworkers demonstrated that MSCs increase the expression of anti-inflammatory cytokine interleukin-10 (Gupta et al. 2007).

\section{Anti-fibrosis}

Multiple groups have documented the anti-fibrotic effects of MSCs. In a study of radiation-induced pulmonary fibrosis in Sprague-Dawley rats, Dong and coworkers showed a decrease in pro-fibrotic transforming growth factor- $\beta$ and tumor necrosis factor- $\alpha$ after systemic MSC instillation (Dong et al. 2015). The authors speculate that MSCs also inhibit lung fibrosis through the secretion of hepatocyte growth factor and prostaglandin. Similarly, a review article of preclinical and clinical studies recapitulates the antifibrotic effects of MSCs in liver fibrosis (Berardis et al. 2015).

Taken together, the growing body of literature demonstrates the potential benefits MSCs may offer in endocrine disorders.

\section{Strategies to enhance MSC survival and function}

To offer regenerative effects to injured cells, transplanted MSCs must first survive the harsh environment of the treated tissue. In this niche, MSCs must overcome various stressors including hypoxia, inflammation, high acidity and decreased energy reserves. Strategies to prolong survival of MSCs long enough to deliver a rich source of restorative factors, include: (i) preconditioning the cells (hypoxia, mechanical stimulation), (ii) genetically modifying the MSCs (viral transfection with promoter-targeted small hairpin RNA to overexpress/silence specific proteins) and (iii) delivering MSCs with biomaterials (scaffolds, hydrogels). This concise review will present two strategic examples.

\section{Hypoxic preconditioning}

Preclinical studies of myocardial infarction revealed that intracardiac injection of hypoxic-treated stem cells 
sustained viability of surrounding cardiac cells, preserved cardiac function and engraftment of cells to the injured heart was higher (Baglio et al. 2015). Work by Zhang and Chacko suggests that MSCs grown in hypoxia induces a pro-survival state (Chacko et al. 2010, Zhang et al. 2016). These findings have also been linked to decreases in nuclear damage, apoptosis and production of lactate dehydrogenase (Bader et al. 2015). Hypoxic preconditioning also increases MSC homing/motility via the stromal-derived factor-1 receptor/CXCR4 transduction pathway, as well as through the focal adhesion kinase and potassium channel Kv2.1 signaling mechanism (Hu et al. 2011).

\section{Vascular endothelial growth factor (genetic) overexpression}

In a rat model of myocardial infarction, overexpressing vascular endothelial growth factor (VEGF) via transfection with a viral vector, protected MSCs against cell death, stimulated vascular growth, improved cardiac function and lessened infarct size (Augustin et al. 2013). Using a mouse model of diabetes, islet transplants treated with MSCs virally transduced to express VEGF demonstrated a lower blood glucose, restored euglycemia quicker after surgery and improved graft vascularization (Hajizadeh-Saffar et al. 2015).

\section{Mesenchymal stem cells to treat diabetes}

The versatile properties of MSCs have generated their clinical interest as therapies for diabetes. To date, over 40 clinical trials are registered using MSCs as therapeutic agents for diabetes. These studies range in scope from diabetes-related vascular complications, to wound healing, and even include MSC therapy to treat new-onset diagnosis. As of 29 May 2017, forty-seven MSC studies for diabetes are registered on clinicaltrials.gov. Here, we will summarize findings from clinical investigations addressing the use of MSC-based therapy for new-onset, as well as chronic, diabetes.

\section{Diabetes mellitus}

In 2015, investigators from Sweden (NCT01068951) reported the first study aimed to evaluate the safety and efficacy of autologous MSC treatment in newly diagnosed type 1 diabetics. Stem cells were harvested from the patient's iliac crest bone marrow and the median systemic single dose was $2.75 \times 10^{6} \mathrm{cells} / \mathrm{kg}$. They concluded that administration of MSCs did not result in adverse events in any of the ten patients and provided promising C-peptide concentrations at the 1-year follow-up. This phase I trial did not show any functional differences between the control and MSC group in hemoglobin $\mathrm{A} 1 \mathrm{c}(\mathrm{HbA1c})$ or insulin dose.

$\mathrm{Hu}$ and coworkers conducted a single-center, double-blind study examining the safety, feasibility and preliminary outcomes of umbilical cord Wharton's jelly-derived MSCs for new-onset type I diabetics ( $\mathrm{Hu}$ et al. 2013). The MSC-treated group underwent two intravenous infusions (mean cell count of $2.6 \times 10^{7}$ ) separated 4 weeks apart. Postprandial glucose and HbA1c measurements were lower in the experimental cohort between 9 and 24 months after MSC infusion. Also, insulin usage and fasting C-peptide were significantly improved in the MSC group. The study authors concluded that in their small study, not powered to detect functional differences, the transplant of umbilical cord MSCs is feasible and safe.

A pilot study in China involving placenta-derived MSCs to patients with long-standing diabetes mellitus type 2 revealed the transplantation was safe, easy and potentially efficacious (Jiang et al. 2011). This investigation included ten patients with type 2 diabetes for a duration $\geq 3$ years, insulin dependent ( $\geq 0.7 \mathrm{U} / \mathrm{kg} /$ day) for at least 1 year and poorly controlled glucose. The subjects received on average $1.35 \times 10^{6} / \mathrm{kg}$ placental stem cells on three separate occasions with 1-month intervals between intravenous infusions. Six months after treatment, the insulin dosage and $\mathrm{HbA1c}$ measurements for all the patients demonstrated a trend toward improvement. Moreover, C-peptide and insulin release were also higher after MSC treatment. In addition, this study included a group of individuals that translate closer to actual clinical scenarios, as they also had other comorbidities, including heart disease, kidney disease and vascular complications.

Lately, researchers have developed insulinsecreting MSCs and delivered them, in combination with hematopoietic stem cells, to patients with type I diabetes (Vanikar et al. 2010, Thakkar et al. 2015). Autologous transplantation via the intrapancreatic route tended to have an improved C-peptide and postprandial glucose at 15-24 months when compared to allogenic transplantation. Both studies viewed the stem cell administration as a safe procedure with potential benefit; however, larger studies will need to be conducted to substantiate their findings.

Table 1 summarizes a list of clinical trials utilizing MSCs for the treatment of diabetes.

Published by Bioscientifica Ltd. 


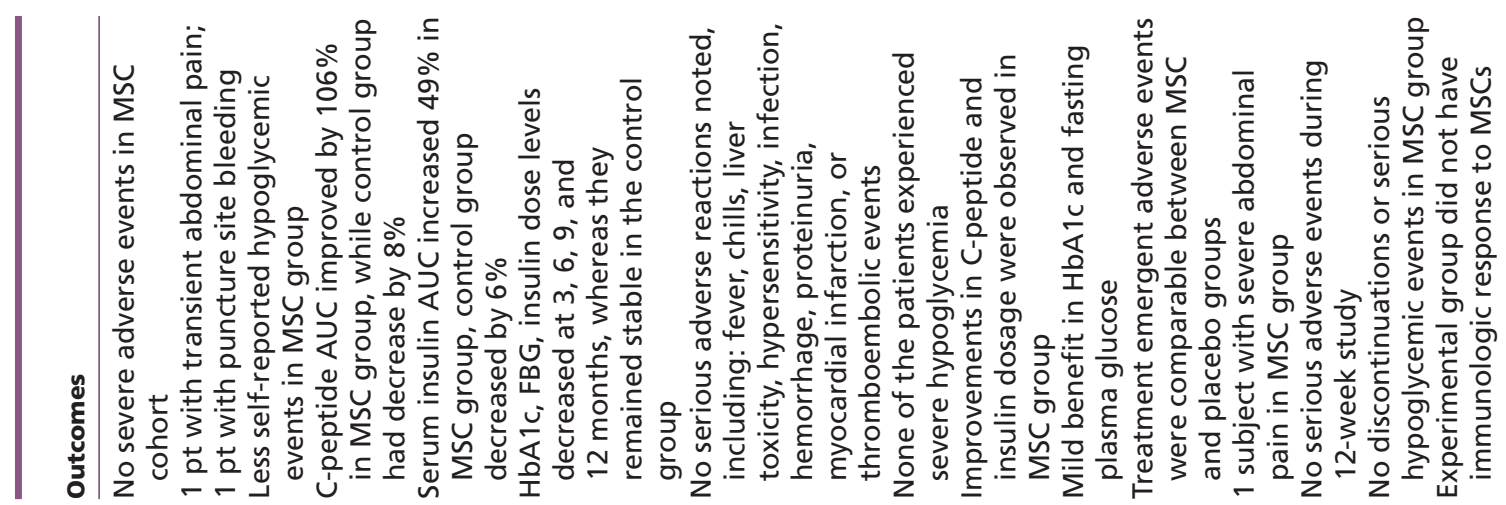

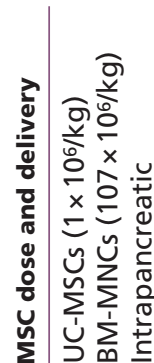

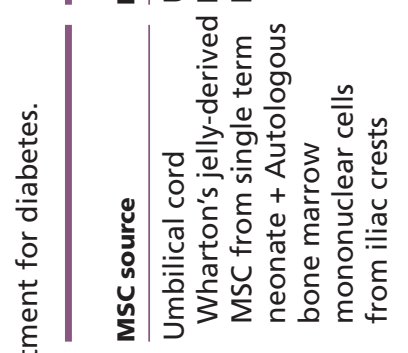

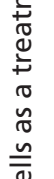

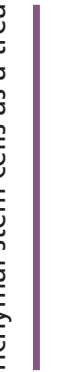

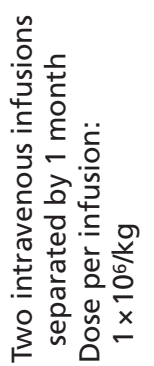

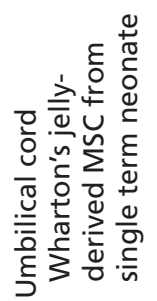

在

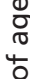

$\stackrel{n}{\stackrel{2}{\pi}}$

일

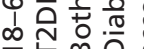

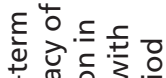

원

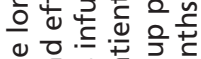

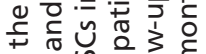

凶 $\sum^{n} \sum$ 응

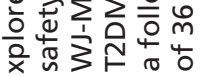

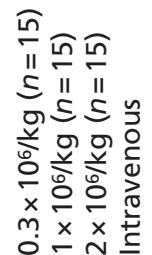

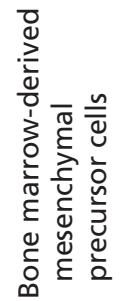

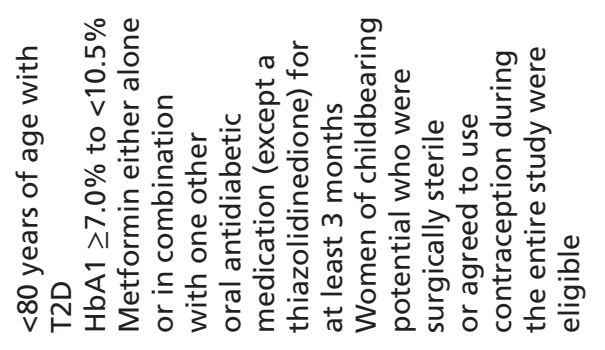

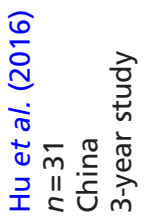

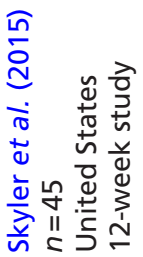

http://jme.endocrinology-journals.org DOI: 10.1530/JME-17-0117 (c) 2017 Society for Endocrinology Printed in Great Britain 

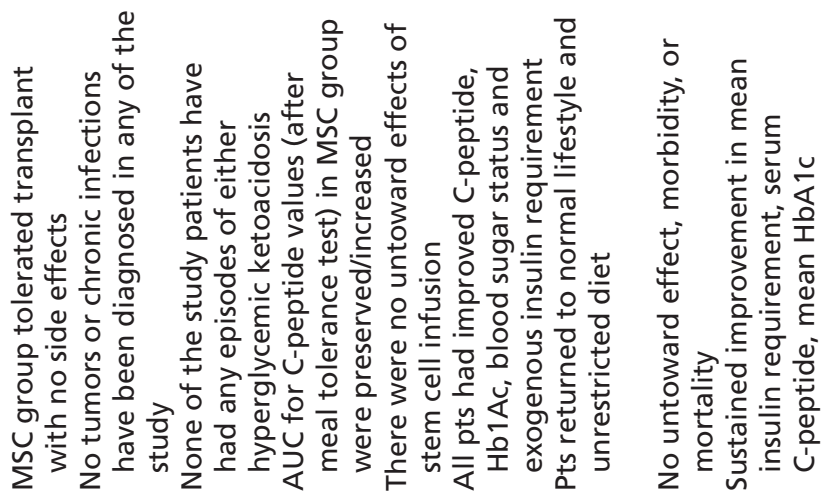

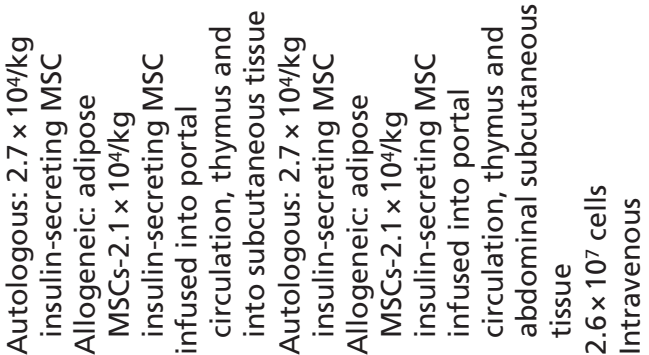
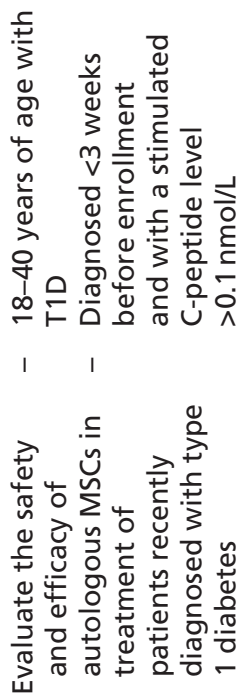

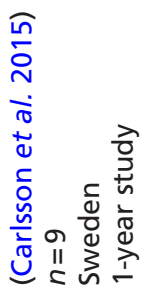

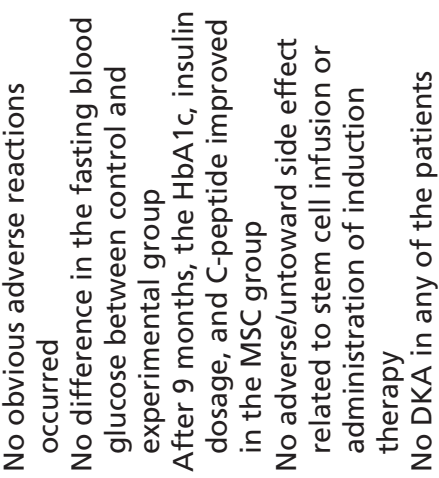

ฮิ
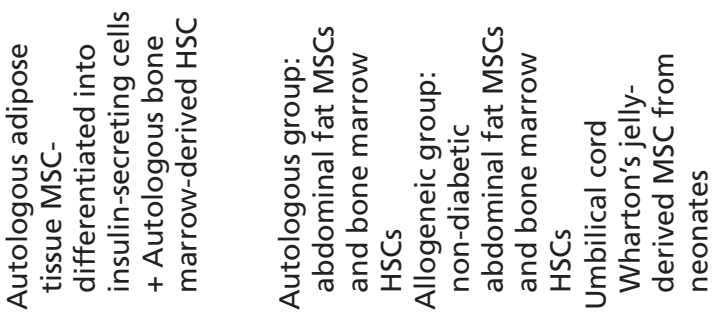

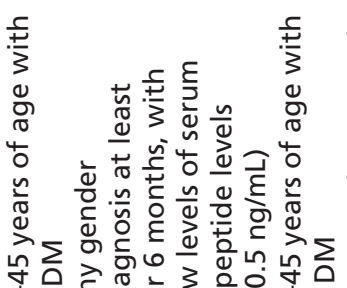

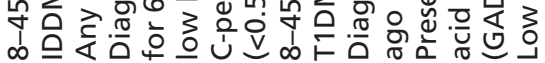

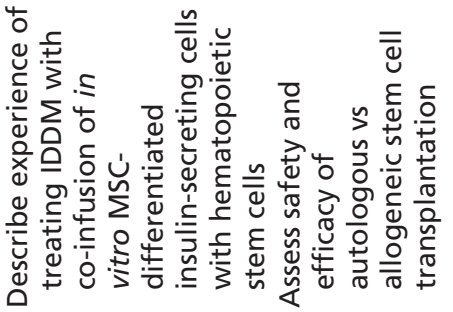

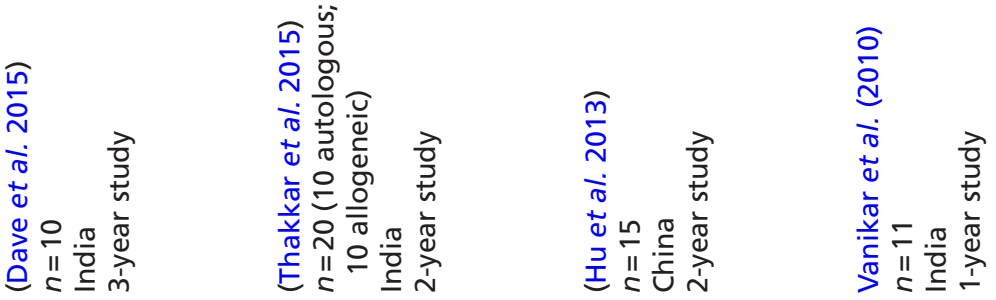

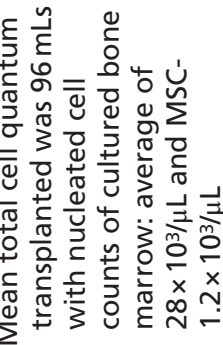

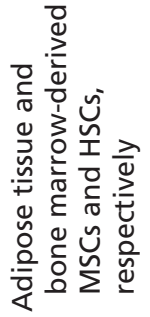

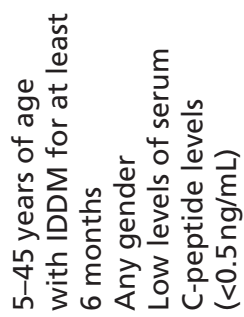

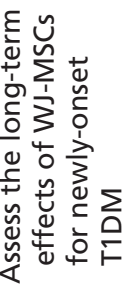

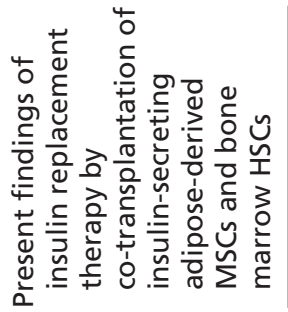



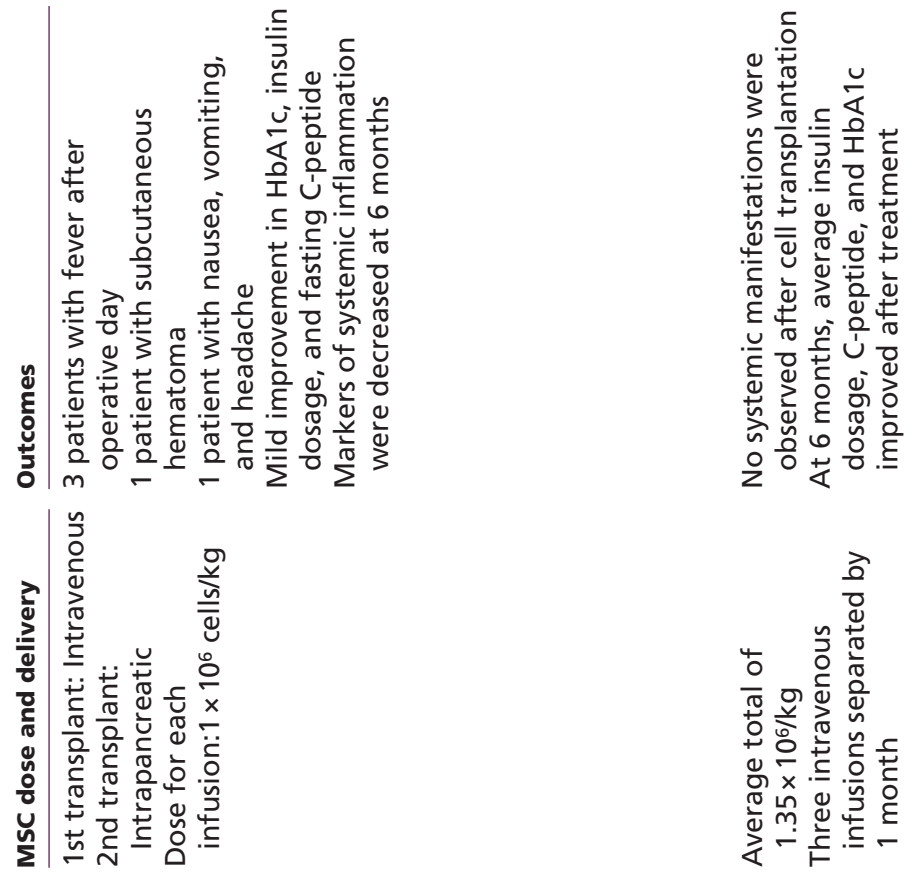

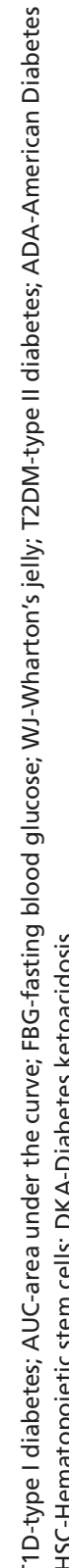
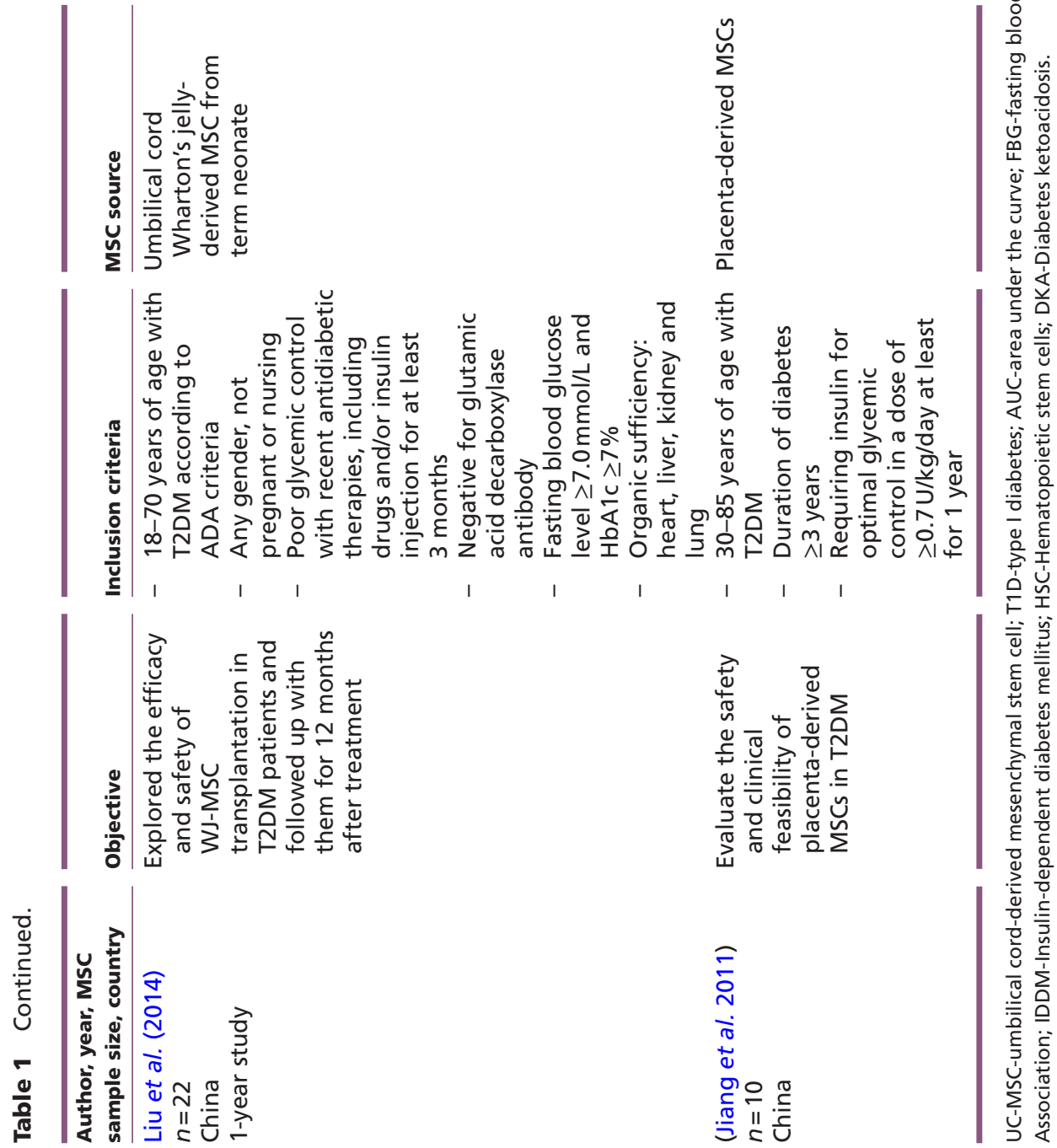


\section{Which diabetic patients would benefit from MSC therapy?}

Given the findings in the meta-analysis by El-Badawy and El-Badri, patients with diabetes type I and II can benefit from MSC therapy (El-Badawy \& El-Badri 2016). Furthermore, the authors discuss that patients in the early stages of diabetes may be among the best candidates for stem cell treatment. Although 22 studies were included in this review, only 6 studies (total of 112 patients) used MSCs, of which only 2 studies focused on early-onset diagnosis (total of 49 patients). Still, the four studies in patients with chronic diabetes type I/II (average 8-year duration) had improvements in diabetic measures, which strongly justifies further studies to clearly delineate potential diabetic populations that may benefit from MSC therapy.

\section{Regulation of cell-based products prior to clinical application}

Thus far, no standardized method for the isolation, characterization, expansion, potency testing, nor pathogen screening for MSCs exists (Arutyunyan et al. 2016, Smith et al. 2016, Weiss et al. 2016). The regulation of cell-based products by the US Food and Drug Administration (FDA) focuses on three main themes: (i) prevention of transmitting communicable disease via contaminated tissue, (ii) proper handling and processing of tissue and (iii) demonstration of clinical safety and effectiveness of cells, especially after extensive manipulation. The FDA also requires tissue processing facilities to register, list their products and provide accurate labeling of the products. Recent review articles have presented specifics focusing on standardization and production of clinicalgrade stem cells (Giancola et al. 2012, Sensebé et al. 2013, Arutyunyan et al. 2016, Smith et al. 2016, Weiss et al. 2016).

\section{Maintenance of umbilical cord MSCs}

Public and private biobanks have been firmly established for the cryopreservation of hematopoietic stem cells from the umbilical cord blood. There has now been a recent option from private banks for the cryopreservation of MSCs from cord tissue, as well as cord blood. However, the cost of banking MSCs can become a concern as the initial charge is between $\$ 1000$ and $\$ 3000$ for collection, processing and preservation (Roura et al. 2012). In addition, the banking centers charge storage costs that amount to a few hundred dollars per year. Researchers from Loughborough University presented a provocative cost-effectiveness analysis of allogeneic induced pluripotent stem cell-derived $\beta$-cell therapy. Assuming the cost of stem cell therapy was approximately $\$ 200,000$, the graft/transplant survival required to achieve costeffectiveness (when compared to insulin therapy) with/ without immunosuppressive therapy was calculated to range between 8 and 11 years. Yet, current evidence indicates that graft $\beta$-cell function for 8-11 years is highly unlikely. A more cost-effective approach may entail a cord blood-derived mesenchymal stem cell administration (Bart 2010).

\section{Allogeneic transplantation of MSCs}

Advantages to allogeneic administration of MSCs include: (i) wide availability, (ii) low cost (iii) and quality control (Sarkar et al. 2010). Although it is well established that MSCs reduce the clinical sequelae of graft vs host disease, some studies question the safety of allografts. For instance, donor MSC infusion in a rat model of skin allograft transplantation induced an immunogenic response (higher TNF- $\alpha$ levels) (Sbano et al. 2008). In Seifert's animal study, pretreating a solid organ transplantation with allogeneic MSCs resulted in a trend to higher inflammatory levels and signs of rejection (Seifert et al. 2012). Despite these findings in the preclinical setting, phase I clinical trials have yet to report rejection/severe immunologic reactions after allogeneic transplantation of MSCs (Haarer et al. 2015). Larger and long-term human studies will need to assess the risk of rejection and/or inflammation secondary to donor-derived MSCs.

\section{Future objectives}

Before widespread use of MSCs (or their derivatives) in clinical medicine, many unresolved questions remain:

- How do we ensure that the MSCs are consistently produced and controlled per standard measures?

- What is the best source, route, dose and number of administrations for clinical effectiveness?

- What are the long-term consequences of cell-based therapies (stem cells, conditioned media, exosomes, etc.)?

- Which strategies and tissue sources yield the best results?

- How do we optimize a scalable line of MSCs that are costeffective for clinical application?

- Should MSCs/cell-based products be conditioned/altered to induce insulin-secreting potential? http://jme.endocrinology-journals.org DOI: 10.1530/JME-17-0117
(C) 2017 Society for Endocrinology Printed in Great Britain 
Unraveling the cross-talk between the endogenous stem cell, exogenous stem cell and their response to the microenvironment is critical in unlocking the potential use of MSCs as therapeutic agents in endocrinologic disorders.

\section{Conclusion}

Given their ability to mitigate fibrosis, modulate inflammation and promote vascular growth, MSCs provide a promising therapeutic strategy for patients with endocrine disorders. The boundless availability of MSCs from various tissues and organs, as well as their beneficial properties, reinforces the widespread use of these cell types in regenerative studies. Although our understanding of factors mediating the function of MSCs has improved, there is still much that is not clearly understood. For instance, newer evidence is demonstrating that preconditioning/ genetically altering MSCs may influence their function and thereby translate to improved clinical effects. Although large studies examining human application of MSCs are still lacking, initial studies in endocrine-focused studies demonstrate the potential for a paradigm shift. In summary, regenerative medicine remains a new and exciting field of research that holds much promise into the treatment of patients with endocrinologic diseases of all ages.

\section{Declaration of interest}

The authors declare that there is no conflict of interest that could be perceived as prejudicing the impartiality of this review.

\section{Funding}

A Moreira: The project described was supported by the National Center for Advancing Translational Sciences, National Institutes of Health, through grant KL2 TR001118. The content is solely the responsibility of the authors and does not necessarily represent the official views of the NIH. This study was also supported by The University of Texas Health San Antonio School of Medicine Clinical Investigator Kickstart Pilot Grant.

\section{Author contribution statement}

A Moreira designed review, wrote final product of manuscript, created table, created Figs 2 and 3; S Kahlenberg wrote first draft of the manuscript, literature search; production of Fig. 1; P Hornsby extensive corrections/modifications, ideas for the manuscript.

\section{References}

Acosta SA, Franzese N, Staples M, Weinbren NL, Babilonia M, Patel J, Merchant N, Simancas AJ, Slakter A, Caputo M, et al. 2013 Human umbilical cord blood for transplantation therapy in myocardial infarction. Journal of Stem Cell Research and Therapy (Suppl 4) S4-005. (doi:10.4172/2157-7633.s4-005)
Arno AI, Amini-Nik S, Blit PH, Al-Shehab M, Belo C, Herer E, Tien CH \& Jeschke MG 2014 Human Wharton's jelly mesenchymal stem cells promote skin wound healing through paracrine signaling. Stem Cell Research and Therapy 5 28. (doi:10.1186/scrt417)

Arutyunyan I, Elchaninov A, Makarov A \& Fatkhudinov T 2016 Umbilical cord as prospective source for mesenchymal stem cellbased therapy. Stem Cells International 2016 article ID 6901286. (doi:10.1155/2016/6901286)

Augustin M, Mahar MAA, Lakkisto P, Tikkanen I, Vento A, Pätilä T \& Harjula A 2013 VEGF overexpression improves mesenchymal stem cell sheet transplantation therapy for acute myocardial infarction. Journal of Tissue Engineering and Regenerative Medicine 7 742-750. (doi:10.1002/term.1471)

Azandeh S, Orazizadeh M, Hashemitabar M, Khodadadi A, Shayesteh AA, Nejad DB, Gharravi AM \& Allahbakhshi E 2012 Mixed enzymatic-explant protocol for isolation of mesenchymal stem cells from Wharton's jelly and encapsulation in 3D culture system. Journal of Biomedical Science and Engineering 5 580-586. (doi:10.4236/ jbise.2012.510071)

Bader AM, Klose K, Bieback K, Korinth D, Schneider M, Seifert M, Choi YH, Kurtz A, Falk V \& Stamm C 2015 Hypoxic preconditioning increases survival and pro-angiogenic capacity of human cord blood mesenchymal stromal cells in vitro. PLoS One 10 9. (doi:10.1371/ journal.pone.0318477)

Baglio SR, Rooijers K, Koppers-Lalic D, Verweij FJ, Pérez Lanzón M, Zini N, Naaijkens B, Perut F, Niessen HWM, Baldini N, et al. 2015 Human bone marrow- and adipose-mesenchymal stem cells secrete exosomes enriched in distinctive miRNA and tRNA species. Stem Cell Research and Therapy 6 127. (doi:10.1186/s13287-015-0116-z)

Bart T 2010 Cost effectiveness of cord blood versus bone marrow and peripheral blood stem cells Clinico Economics and Outcomes Research 2 141-147. (doi:10.2147/CEOR.S11210)

Berardis S, Dwisthi Sattwika P, Najimi M \& Sokal EM 2015 Use of mesenchymal stem cells to treat liver fibrosis: current situation and future prospects. World Journal of Gastroenterology 21 742-758. (doi:10.3748/wjg.v21.i3.742)

Birmingham E, Niebur GL, McHugh PE, Shaw G, Barry FP \& McNamara LM 2012 Osteogenic differentiation of mesenchymal stem cells is regulated by osteocyte and osteoblast cells in a simplified bone niche. European Cells and Materials 23 13-27. (doi:10.22203/eCM.v023a02)

Boeuf S, Richter W, Richter W, Brittberg M, Lindahl A, Nilsson A, Ohlsson C, Isaksson O, Peterson L, Friedenstein A, et al. 2010 Chondrogenesis of mesenchymal stem cells: role of tissue source and inducing factors. Stem Cell Research and Therapy 1 31. (doi:10.1186/scrt31)

Bruyn D, Najar M, Raicevic G, Meuleman N, Pieters K, Stamatopoulos B, Delforge A, Bron D \& Lagneaux L 2011 A rapid, simple, and reproducible method for the isolation of mesenchymal stromal cells from Wharton's jelly without enzymatic treatment. Stem Cells and Development 20 547-557. (doi:10.1089/scd.2010.0260)

Cai J, Wu Z, Xu X, Liao L, Chen J, Huang L, Wu W, Luo F, Wu C, Pugliese A, et al. 2016 Umbilical cord mesenchymal stromal cell with autologous bone marrow cell transplantation in established type 1 diabetes: a pilot randomized controlled open-label clinical study to assess safety and impact on insulin secretion. Diabetes Care $\mathbf{3 9}$ 149-157. (doi:10.2337/dc15-0171)

Caplan AI \& Correa D 2011 The MSC: an injury drugstore. Cell Stem Cell 9 11-15. (doi:10.1016/j.stem.2011.06.008)

Carlsson P-O, Schwarcz E, Korsgren O \& Le Blanc K 2015 Preserved $\beta$-cell function in type 1 diabetes by mesenchymal stromal cells. Diabetes 64 587-592. (doi:10.2337/db14-0656)

Chacko SM, Ahmed S, Selvendiran K, Kuppusamy ML, Khan M \& Kuppusamy P 2010 Hypoxic preconditioning induces the expression of prosurvival and proangiogenic markers in mesenchymal stem cells. American Journal of Physiology: Cell Physiology 6 1562-1570. (doi:10.1152/ajpcell.00221.2010) 
Dave SD, Vanikar AV, Trivedi HL, Thakkar UG, Gopal SC \& Chandra T 2015 Novel therapy for insulin-dependent diabetes mellitus: infusion of in vitro-generated insulin-secreting cells. Clinical and Experimental Medicine 15 41-45. (doi:10.1007/s10238-013-0266-1)

Dominici M, Le Blanc K, Mueller I, Slaper-Cortenbach I, Marini F, Krause D, Deans R, Keating A, Prockop D \& Horwitz E 2006 Minimal criteria for defining multipotent mesenchymal stromal cells. The International Society for Cellular Therapy position statement. Cytotherapy 8 315-317. (doi:10.1080/14653240600855905)

Dong L-H, Jiang Y-Y, Liu Y-J, Cui S, Xia C-C, Qu C, Jiang X, Qu Y-Q, Chang P-Y \& Liu F 2015 The anti-fibrotic effects of mesenchymal stem cells on irradiated lungs via stimulating endogenous secretion of HGF and PGE2. Scientific Reports 5 8713. (doi:10.1038/srep08713)

El-Badawy A \& El-Badri N 2016 Clinical efficacy of stem cell therapy for diabetes mellitus: a meta-analysis. PLoS ONE 11 e0151938. (doi:10.1371/journal.pone.0151938)

El-Demerdash RF, Hammad LN, Kamal MM \& El Mesallamy HO 2015 A comparison of Wharton's jelly and cord blood as a source of mesenchymal stem cells for diabetes cell therapy. Regenerative Medicine 10 841-855. (doi:10.2217/rme.15.49)

Fan L, Zhang C, Yu Z, Shi Z, Dang X \& Wang K 2015 Transplantation of hypoxia preconditioned bone marrow mesenchymal stem cells enhances angiogenesis and osteogenesis in rabbit femoral head osteonecrosis. Bone 81 544-553. (doi:10.1016/j.bone.2015.09.005)

Feng Y, Wang J, Ling S, Li Z, Li M, Li Q, Ma Z \& Yu S 2014 Differentiation of mesenchymal stem cells into neuronal cells on fetal bovine acellular dermal matrix as a tissue engineered nerve scaffold. Neural Regeneration Research 9 1968-1978. (doi:10.4103/ 1673-5374.145378)

Fong C-Y, Chak L-L, Biswas A, Tan J-H, Gauthaman K, Chan W-K \& Bongso A 2011 Human Wharton's jelly stem cells have unique transcriptome profiles compared to human embryonic stem cells and other mesenchymal stem cells. Stem Cell Reviews and Reports 7 1-16. (doi:10.1007/s12015-010-9166-x)

Giancola R, Bonfini T \& Iacone A 2012 Cell therapy: cGMP facilities and manufacturing. Muscles, Ligaments and Tendons Journal 2 243-247.

Gupta N, Su X, Popov B, Lee JW, Serikov V, Matthay MA, Gupta N, Su X, Popov B, Lee JW, et al. 2007 Intrapulmonary delivery of bone marrow-derived mesenchymal stem cells improves survival and attenuates endotoxin-induced acute lung injury in mice 1. Journal of Immunology 179 1855-1863. (doi:10.4049/jimmunol.179.3.1855)

Haarer J, Johnson CL, Soeder Y \& Dahlke MH 2015 Caveats of mesenchymal stem cell therapy in solid organ transplantation. Transplant International 28 1-9. (doi:10.1111/tri.12415)

Hajizadeh-Saffar E, Tahamtani Y, Aghdami N, Azadmanesh K, HabibiAnbouhi M, Heremans Y, De Leu N, Heimberg H, Ravassard P, Shokrgozar MA, et al. 2015 Inducible VEGF expression by human embryonic stem cell-derived mesenchymal stromal cells reduces the minimal islet mass required to reverse diabetes. Scientific Reports $\mathbf{5}$ 9322. (doi:10.1038/srep09322)

Hammes H-P, Feng Y, Pfister F \& Brownlee M 2011 Diabetic retinopathy: targeting vasoregression. Diabetes 60 9-16. (doi:10.2337/db10-0454)

Hiew V, Fatimah S \& Teoh L 2016 Comparison of explant-derived and enzymatic digestion-derived mesenchymal stem cells from Wharton's jelly. Frontiers in Bioengineering and Biotechnology (abstract). (doi:10.3389/conf.FBIOE.2016.02.00030)

Hsuan YC-Y, Lin C-H, Chang C-P \& Lin M-T 2016 Mesenchymal stem cell-based treatments for stroke, neural trauma, and heat stroke. Brain and Behavior 6 e00526. (doi:10.1002/brb3.526)

Hu X, Wei L, Taylor TM, Wei J, Zhou X, Wang J-A \& Yu SP 2011 Hypoxic preconditioning enhances bone marrow mesenchymal stem cell migration via Kv2.1 channel and FAK activation. American Journal of Physiology: Cell Physiology 301 C362-C372. (doi:10.1152/ ajpcell.00013.2010)

Hu J, Yu X, Wang Z, Wang F, Wang L, Gao H, Chen Y, Zhao W, Jia Z, Yan S, et al. 2013 Long term effects of the implantation of Wharton's jelly-derived mesenchymal stem cells from the umbilical cord for newly-onset type 1 diabetes mellitus. Endocrine Journal 60 347-357. (doi:10.1507/endocrj.EJ12-0343)

Hu J, Wang Y, Gong H, Yu C, Guo C, Wang F, Yan S \& Xu H 2016 Long term effect and safety of Wharton's jelly-derived mesenchymal stem cells on type 2 diabetes. Experimental and Therapeutic Medicine 12 1857-1866. (doi:10.3892/etm.2016.3544)

Jiang R, Han Z, Zhuo G, Qu X, Li X, Wang X, Shao Y, Yang S \& Han ZC 2011 Transplantation of placenta-derived mesenchymal stem cells in type 2 diabetes: a pilot study. Frontiers of Medicine 5 94-100. (doi:10.1007/s11684-011-0116-z)

Johnson KE \& Wilgus TA 2014 Vascular endothelial growth factor and angiogenesis in the regulation of cutaneous wound repair. Advances in Wound Care 3 647-661. (doi:10.1089/wound.2013.0517)

Keilhoff G, Goihl A, Langnase K, Fansa H \& Wolf G 2006 Transdifferentiation of mesenchymal stem cells into Schwann celllike myelinating cells. European Journal of Cell Biology 85 11-24. (doi:10.1016/j.ejcb.2005.09.021)

Liu X, Zheng P, Wang X, Dai G, Cheng H, Zhang Z, Hua R, Niu X, Shi J $\&$ An Y 2014 A preliminary evaluation of efficacy and safety of Wharton's jelly mesenchymal stem cell transplantation in patients with type 2 diabetes mellitus. Stem Cell Research and Therapy 557. (doi:10.1186/scrt446)

Mauck RL, Yuan X \& Tuan RS 2006 Chondrogenic differentiation and functional maturation of bovine mesenchymal stem cells in longterm agarose culture. Osteoarthritis and Cartilage 14 179-189. (doi:10.1016/i.joca.2005.09.002)

Monteiro R \& Azevedo I 2010 Chronic inflammation in obesity and the metabolic syndrome. Mediators of Inflammation 2010 article ID 289645. (doi:10.1155/2010/289645)

Mori Y, Ohshimo J, Shimazu T, He H, Takahashi A, Yamamoto Y, Tsunoda H, Tojo A \& Nagamura-Inoue T 2015 Improved explant method to isolate umbilical cord-derived mesenchymal stem cells and their immunosuppressive properties. Tissue Engineering Part C, Methods 21 367-372. (doi:10.1089/ten.TEC.2014.0385)

Moshtagh PR, Emami SH \& Sharifi AM 2013 Differentiation of human adipose-derived mesenchymal stem cell into insulin-producing cells: an in vitro study. Journal of Physiology and Biochemistry 69 451-458. (doi:10.1007/s13105-012-0228-1)

Murphy MB, Moncivais K \& Caplan AI 2013 Mesenchymal stem cells: environmentally responsive therapeutics for regenerative medicine. Experimental and Molecular Medicine 45 e54. (doi:10.1038/ emm.2013.94)

Nagamura-Inoue T \& Mukai T 2015 Umbilical cord is a rich source of mesenchymal stromal cells for cell therapy. Current Stem Cell Research and Therapy 11 634-642. (doi:10.2174/15748 $88 \times 10666151026115017)$

Paneni F, Beckman JA, Creager MA \& Cosentino F 2013 Diabetes and vascular disease: pathophysiology, clinical consequences, and medical therapy: part I. European Heart Journal 34 2436-2443. (doi:10.1093/eurheartj/eht149)

Pers Y-M, Ruiz M, Noël D \& Jorgensen C 2015 Mesenchymal stem cells for the management of inflammation in osteoarthritis: state of the art and perspectives. Osteoarthritis and Cartilage 23 2027-2035. (doi:10.1016/j.joca.2015.07.004)

Rostamzadeh A, Anjomshoa M, Kurd S, Chai J-K, Jahangiri F, Nilforoushzadeh MA \& Zare S 2015 The role of Wharton's jelly mesenchymal stem cells in skin reconstruction. Journal of Skin and Stem Cell 2. (doi:10.17795/jssc30347)

Roura S, Pujal J-M, Gálvez-Montón C \& Bayes-Genis A 2012 Generation of disease-specific induced pluripotent stem cells from patients with different karyotypes of Down syndrome. Stem Cell Research \& Therapy 3 14. (doi:10.1186/scrt105)

Salehinejad P, Alitheen NB, Ali AM, Omar AR, Mohit M, Janzamin E, Samani FS, Torshizi Z \& Nematollahi-Mahani SN 2012 Comparison of different methods for the isolation of mesenchymal stem cells 
from human umbilical cord Wharton's jelly. In Vitro Cellular and Developmental Biology - Animal 48 75-83. (doi:10.1007/ s11626-011-9480-x)

Sarkar D, Vemula PK, Zhao W, Gupta A, Karnik R, Karp JM \& Hu D 2010 Engineered mesenchymal stem cells with self-assembled vesicles for systemic cell targeting. Biomaterials 31 5266-5274. (doi:10.1016/j. biomaterials.2010.03.006)

Sbano P, Cuccia A, Mazzanti B, Urbani S, Giusti B, Lapini I, Rossi L, Abbate R, Marseglia G, Nannetti G, et al. 2008 Use of donor bone marrow mesenchymal stem cells for treatment of skin allograft rejection in a preclinical rat model. Archives of Dermatological Research 300 115-124. (doi:10.1007/s00403-007-0827-9)

Scott MA, Nguyen VT, Levi B \& James AW 2011 Current methods of adipogenic differentiation of mesenchymal stem cells. Stem Cells and Development 20 1793-1804. (doi:10.1089/scd.2011.0040)

Seifert M, Stolk M, Polenz D \& Volk H-D 2012 Detrimental effects of rat mesenchymal stromal cell pre-treatment in a model of acute kidney rejection. Frontiers in Immunology 3 202. (doi:10.3389/ fimmu.2012.00202)

Sensebé L, Gadelorge M \& Fleury-Cappellesso S 2013 Production of mesenchymal stromal/stem cells according to good manufacturing practices: a review. Stem Cell Research and Therapy 4 66. (doi:10.1186/ scrt217)

Skyler JS, Fonseca VA, Segal KR \& Rosenstock J 2015 Allogeneic mesenchymal precursor cells in type 2 diabetes: a randomized, placebo-controlled, dose-escalation safety and tolerability pilot study. Diabetes Care 38 1742-1749. (doi:10.2337/dc14-2830)

Smith JR, Pfeifer K, Petry F, Powell N, Delzeit J \& Weiss ML 2016 Standardizing umbilical cord mesenchymal stromal cells for translation to clinical use: selection of GMP-compliant medium and a simplified isolation method. Stem Cells International 2016 1-14. (doi:10.1155/2016/6810980)

Talaei-Khozani T, Borhani-Haghighi M, Ayatollahi M \& Vojdani Z 2015 An in vitro model for hepatocyte-like cell differentiation from Wharton's jelly derived-mesenchymal stem cells by cell-base aggregates. Gastroenterology and Hepatology from Bed to Bench 8 188-199.

Thakkar UG, Trivedi HL, Vanikar AV \& Dave SD 2015 Insulin-secreting adipose-derived mesenchymal stromal cells with bone marrowderived hematopoietic stem cells from autologous and allogenic sources for type 1 diabetes mellitus. Cytotherapy 17 940-947. (doi:10.1016/j.jcyt.2015.03.608)

Thibault RA, Scott Baggett L, Mikos AG \& Kasper FK 2010 Osteogenic differentiation of mesenchymal stem cells on pregenerated extracellular matrix scaffolds in the absence of osteogenic cell culture supplements. Tissue Engineering Part A 16 431-440. (doi:10.1089/ten.TEA.2009.0583)

Vangsness CT, Sternberg H \& Harris L 2015 Umbilical cord tissue offers the greatest number of harvestable mesenchymal stem cells for research and clinical application: a literature review of different harvest sites. Arthroscopy 31 1836-1843. (doi:10.1016/j. arthro.2015.03.014)

Vanikar AV, Dave SD, Thakkar UG \& Trivedi HL 2010 Cotransplantation of adipose tissue-derived insulin-secreting mesenchymal stem cells and hematopoietic stem cells: a novel therapy for insulin-dependent diabetes mellitus. Stem Cells International 2010 1-5. (doi:10.4061/2010/582382)

Wang L, Zhao Y \& Shi S 2012 Interplay between mesenchymal stem cells and lymphocytes: implications for immunotherapy and tissue regeneration. Journal of Dental Research 91 1003-1010. (doi:10.1177/0022034512460404)

Wei L, Fraser JL, Lu Z-Y, Hu X \& Yu SP 2012 Transplantation of hypoxia preconditioned bone marrow mesenchymal stem cells enhances angiogenesis and neurogenesis after cerebral ischemia in rats. Neurobiology of Disease 46 635-645. (doi:10.1016/j.nbd.2012.03.002)

Weiss ML \& Troyer DL 2006 Stem cells in the umbilical cord. Stem Cell Reviews 2 155-162. (doi:10.1007/s12015-006-0022-y)

Weiss ML, Rao MS, Deans R \& Czermak P 2016 Manufacturing cells for clinical use. Stem Cells International 2016 1-5. (doi:10.1155/2016/1750697)

Westhrin M, Xie M, Olderøy MØ, Sikorski P, Strand BL, Standal T, Szpalski C, Wetterau M, Barr J, Warren S, et al. 2015 Osteogenic differentiation of human mesenchymal stem cells in mineralized alginate matrices. PLoS One $\mathbf{1 0}$ e0120374. (doi:10.1371/journal. pone.0120374)

Zhang Y, Lei W, Yan W, Li X, Wang X, Zhao Z, Hui J, Shen Z, Yang J 2016 microRNA-206 is involved in survival of hypoxia preconditioned mesenchymal stem cells through targeting Pim-1 kinase. Stem Cell Research \& Therapy 761. (doi:10.1186/s/3287-016-0318-2)

Received in final form 18 July 2017

Accepted 24 July 2017

Accepted Preprint published online 24 July 2017 http://jme.endocrinology-journals.org DOI: 10.1530/JME-17-0117
๑ 2017 Society for Endocrinology Printed in Great Britain
Published by Bioscientifica Ltd. 